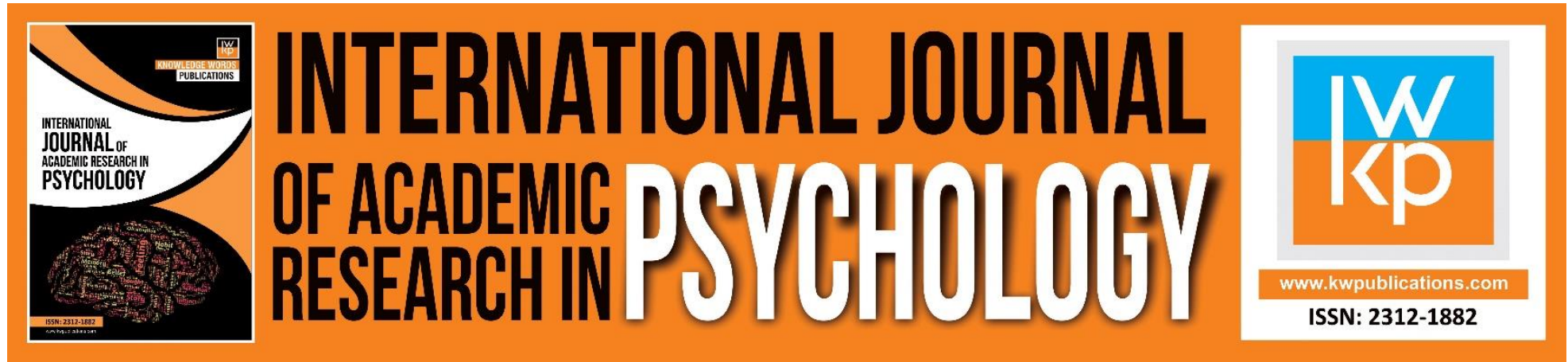

\title{
The Relationship between Anxiety, Depression, and Quality of Life among Women with Breast Cancer
}

\author{
Majid Sadoughi, Zahra Mohammad Salehi
}

To Link this Article: http://dx.doi.org/10.46886/IJARP/v4-i1/2602

DOI: $10.46886 /$ IJARP/v4-i1/2602

Received: 04 February 2017, Revised: 15 March 2017, Accepted: 17 April 2017

Published Online: 29 April 2017

In-Text Citation: (Sadoughi, \& Salehi, 2017)

To Cite this Article: Sadoughi, M., \& Salehi, Z. M. (2017). The Relationship between Anxiety, Depression, and Quality of Life among Women with Breast Cancer. International Journal of Academic Research in Psychology. 4(1), 11-19.

Copyright: (C) 2017 The Author(s)

Published by Knowledge Words Publications (www.kwpublications.com)

This article is published under the Creative Commons Attribution (CC BY 4.0) license. Anyone may reproduce, distribute, translate and create derivative works of this article (for both commercial and non-commercial purposes), subject to full attribution to the original publication and authors. The full terms of this license may be seen at: $\underline{\text { http://creativecommons.org/licences/by/4.0/legalcode }}$

Vol. 4, No. 1, 2017, Pg. 11 - 19

https://kwpublications.com/journals/journaldetail/IJARP

JOURNAL HOMEPAGE

Full Terms \& Conditions of access and use can be found at https://kwpublications.com/pages/detail/publication-ethics 


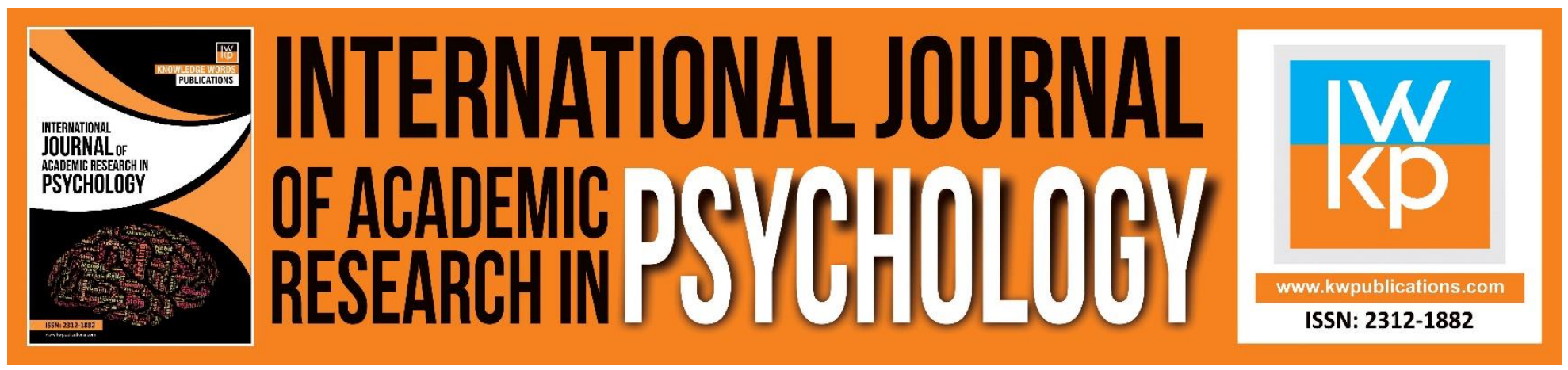

\title{
The Relationship between Anxiety, Depression, and Quality of Life among Women with Breast Cancer
}

\author{
Majid Sadoughi \\ Assistant Professor of Psychology, University of Kashan, Iran \\ Zahra Mohammad Salehi \\ MA student of Educational Psychology, University of Kashan, Iran
}

\begin{abstract}
Anxiety and depression, as common psychological disturbances among patients with breast cancer, might negatively influence their quality of life. The present study aims to explore the relationship between anxiety and depression, in one hand, and quality of life, in the other hand, among these patients. In the present correlational study, 97 women with breast cancer referring to Seyedoshohada Hospital, Isfahan, Iran, were selected through simple random sampling. The participants filled out Life Orientation Test (LOT), Snyder Adult Hope Scale, and Hospital Anxiety and Depression Scale (HADS). Pearson product moment correlation and independent samples $t$-test were run in SPSS (version 22) to analyze the data. The mean of anxiety, depression, and Quality of Life were $10.21 \pm 4.79,8.31 \pm 4.74$, and $63.74 \pm 19.20$, respectively. The total score of anxiety and depression was 18.53 \pm 9.02 . The Pearson correlation coefficient indicated a statistically significant inverse relationship between Quality of Life and anxiety $(r=-.48, p<.01)$ as well as depression $(r=-.52, p<.01)$, indicating patients with more anxiety and depression had lower quality of life. Therefore, it is highly suggested that, along with conventional treatments, initial assessment and screening of anxiety and depression be paid more attention, and necessary interventions be made to reduce them among patients with breast cancer, enhancing these patients' quality of life.
\end{abstract}

Keywords: Breast Cancer, Anxiety, Depression, Quality of Life.

\section{Introduction}

Cancer is a major public health problem throughout the world(Bektas \& Demir, 2016). Causing a large number of deaths, it increases the risk of psychiatric diseases (Tokgoz, 2008). One-third of patients with cancer have mental health disorders and are in dire need of appropriate psychological treatment (Singer, Das-Munshi, \& Brahler, 2009). Rajandram et al ( 2011 )maintains, anxiety and depression are widely known as common psychological distresses among most patients with cancer. In fact, anxiety and depression are caused, to a great extent, by surgical interventions, long-term and intensive 
treatments such as radiotherapy and chemotherapy, and uncertainties during disease progression (Dedeli, Fadiloglu, \& Uslu, 2008). Diagnosis and treatment of cancer might produce significant changes for both cancer patients and their family members in their relationships, roles, and psychological health (Ferrell et al., 1997). Cancer is usually accompanied by much stress as families encounter several challenges in the treatment process, producing a negative impact on their quality of life (QOL) (Petrie, Logan, \& DeGrasse, 2001).

Quality of life reflects the patient's perception of well-being. It has several functioning aspects such as psychological, physical, cognitive, and social (O'Neil et al., 2013). It is one of the criteria proposed for measuring health. More specifically, as the World Health Organization (WHO) has suggested, health is not just lack of disease but the existence of a state of complete physical, mental, and social welfare (Hussein, 2011). Much attention has been paid to quality of life among researchers. Li and Yuan(2011) found that anxiety, depression, and quality of life are affected by demographic and socioeconomic factors such as age, social support, financial status. Psychological and QoL assessment are important in that they can be good predictors for a patient's survival (Bredal et al., 2011).

Overall, considering recent developments in cancer treatment, patients with cancer have higher chances of survival and expect to live with less functional loss and higher quality of life. Therefore, problems concerning the quality of life have internationally drawn the attention of several researchers (Karakoyun-Celik et al., 2010). As one of the important aspects of quality of life and an essential part of clinical oncology, psychological well-being is considered very important for patients with malignant diseases who are constantly dealing with their psychological distress (Brown, McMillan, \& Milroy, 2005). The symptoms of cancer therapy affect cancer patients' quality of life (Demir, 2015). Several studies have shown that anxiety and depression, which occur during the diagnosis and treatment of cancer, increase physical and psychological symptoms, negatively affect quality of life, and decrease treatment adaptation (Kutlu et al., 2011; Satin, Linden, \& Phillips, 2009). Bektas and Demir (2016) found that as the duration of diseases increases, anxiety and depression increase, leading to decreased quality of life. There have been few attempts to explore the relationship between quality of life and anxiety and depression among female patients with cancer. Moreover, due to cultural differences, using depression and quality of life scales developed specifically for western cultures might produce different results in other cultures and societies. Studying German, Japanese, and South Korean patients with breast cancer found that depression is a critical psychological factor affecting the quality of life (Shim, et al., 2006). In their cross-cultural research, depression was found to significantly decrease the quality of life of German and Japanese patients; moreover, none of the stress factors including depression anxiety, and post-traumatic stress disorder were reported to have a negative effect on the quality of life in South Korean patients. Considering these cultural difference, it is necessary to investigate this phenomenon among Iranian patients. However, our extensive review of literature found no study exploring the relationship between anxiety, depression, and quality of life among Iranian female patients with cancer. The current study aims to examine depression, anxiety, and quality of life among Iranian women with breast cancer under chemotherapy.

\section{Method}

The present study was descriptive and cross-sectional with a correlational design. Using simple random sampling, 97 patients with breast cancer referring to Seyedoshohada Hospital, Isfahan, were 
selected. The inclusion criteria were as follows: only patients within the age range of 20-60 years old who had been diagnosed with breast cancer at least six month before were chosen; moreover, they had not taken any psychiatric drug at least six month before, did not suffer any other chronic disease, and had no substance abuse history. The aforementioned criteria were examined based on the patients' records and self-reports. Using SPSS (version 22), the data were analyzed through descriptive statistics (mean, standard deviation) and inferential statistics (Pearson product moment correlation, one-way ANOVA). The data collection instruments included demographic questions, Hospital Anxiety and Depression Scale (HADS), Cancer Quality-of-Life Questionnaire C30 (EORTC QLQC30), all of which were administered with written informed consent.

\section{Instruments}

The Hospital Anxiety and Depression Scale: This instrument, designed by Zigmond and Snaith in 1983 , is widely used to screen for psychiatric problems and assess depression and anxiety in outpatients. It has two subscales, namely, anxiety, and depression, each of which has seven items rated on a four-point Likert scale. The cutoff point has been suggested as 11, and any score higher than this is of clinical importance (Tsunoda et al., 2005) Using an Iranian sample, the Cronbach's alpha of anxiety and depression subscales were reported as .85 and .71, respectively. In the current study, the Cronbach's alpha was calculated .82 and .84 for anxiety and depression subscales.

\section{EORTC Quality-of-Life Questionnaire C30 (QLQ-C30)}

The EORTC QLQ-C30 has been developed for cancer patients' self-assessment of their quality of life. The QLQ-C30 is a 30-item instrument that evaluates, in a multi-dimensional format (a four-point scale, from "not at all" to "very much," for items 1 to 28; a seven-point scale for items 29 and 30), several areas of QoL. The functioning scales evaluate physical function (PF), role function (RF), cognitive function (CF), emotional function (EF), social function (SF), and global QoL. The symptom scales assess physical symptoms commonly reported by patients with cancer like fatigue, pain, dyspnea, insomnia, loss of appetite, and so on (Tsunoda et al., 2005). This instrument has been validated in an Iranian sample, indicating an acceptable validity and reliability (Safaee \& Moghimi Dehkordi, 2007). The Cronbach's alpha reliability coefficient was calculated as .89 in the current study.

\section{Results}

Table 1 shows the frequency and percentage of the participants in addition to mean and standard deviation of their global health status/QoL, anxiety, and depression based on age and SES. 
INTERNATIONAL JOURNAL OF ACADEMIC RESEARCH IN PSYCHOLOGY

Vol. 4, No. 1, 2017, E-ISSN: 2312-1882 @ 2017 KWP

Table 1. Descriptive statistics of global health status/QoL, anxiety, and depression based on age and SES

\begin{tabular}{llllll}
\hline & & $\mathrm{N}$ (percent) & Total QoL & Anxiety & Depression \\
\hline Age & $20-30$ & $8(8.2)$ & $68.75 \pm 16.51$ & $6.84 \pm 3.03$ & $9.87 \pm 2.03$ \\
\cline { 2 - 6 } & $30-40$ & $23(23.7)$ & $65.57 \pm 20.76$ & $10.04 \pm 5.23$ & $8.26 \pm 4.60$ \\
\cline { 2 - 6 } & $40-50$ & $37(38.1)$ & $64.18 \pm 19.23$ & $10.12 \pm 4.67$ & $7.8 \pm 4.89$ \\
\cline { 2 - 6 } & $50-60$ & $29(29.9)$ & $60.34 \pm 18.98$ & $10.55 \pm 5.28$ & $9.35 \pm 5.08$ \\
\cline { 2 - 6 } & Statistical test & $\mathrm{F}=.55, \mathrm{P}=.64$ & $\mathrm{~F}=.073, \mathrm{P}=.97$ & $\mathrm{~F}=.81, \mathrm{P}=.48$ \\
\hline SES & High & $54(55.7)$ & $56.94 \pm 17.11$ & $7.30 \pm 4.47$ & $5.7 \pm 3.89$ \\
\cline { 2 - 6 } & average & $23(23.7)$ & $65.21 \pm 16.21$ & $9.71 \pm 4.53$ & $7.00 \pm 4.33$ \\
\cline { 2 - 6 } & Low & $20(20.6)$ & $80.41 \pm 17.78$ & $11.49 \pm 4.57$ & $9.82 \pm 4.71$ \\
\cline { 2 - 6 } & Statistical test & $\mathrm{F}=13.94, \mathrm{P}=0.00$ & $\mathrm{~F}=6.4, \mathrm{P}=.001$ & $\mathrm{~F}=7.36, \mathrm{P}=.001$ \\
\hline
\end{tabular}

The results of one-way ANOVA (Table 1 ) showed that there is no statistically significant difference among different age groups in terms of their global health status/QoL ( $F=.55, P=.64$ ); however, there is a statistically significant difference among patients with different SES levels in terms of global health status/QoL. As to anxiety and depression, no statistically significant difference was found among different age groups. Moreover, there is a statistically difference among patients with different SES levels in terms of depression; more specifically, post hoc analysis showed that patients with average and high SES levels experience less depression than patients with low SES levels, but there was no statistically significant difference between patients with average and high SES in terms of depression. Furthermore, there is a statistically significant difference among all SES levels in terms of anxiety, and patients with average and high SES experience less anxiety than patients with low SES levels.

Table 2. Descriptive statistics and correlations of QoL and its aspects with anxiety and depression

\begin{tabular}{|c|c|c|c|c|}
\hline Variable & Mean & SD & Anxiety & Depression \\
\hline 1. Quality of life & 63.74 & 19.20 & $-.48^{\star \star}$ & $-.52^{\star \star}$ \\
\hline 2. Physical functioning & 62.19 & 22.74 & -.18 & $-.24^{\star}$ \\
\hline 3. Role play functioning & 59.10 & 29.56 & $-.38^{\star \star}$ & $-.51^{\star \star}$ \\
\hline 4. Emotional functioning & 42.18 & 29.96 & $-.69^{\star \star}$ & $-.65^{\star \star}$ \\
\hline 5. Cognitive functioning & 59.10 & 29.95 & $-.58^{\star \star}$ & $-.48^{\star \star}$ \\
\hline 6. Social functioning & 55.94 & 31.67 & $-.47^{\star \star}$ & $-.51^{\star \star}$ \\
\hline
\end{tabular}

According to Table 2, there is a significant negative correlation between global health status/QoL and its aspects, in one hand, and depression, in the other hand. Moreover, anxiety has a significant negative correlation with global health status/QoL and its aspects except physical functioning.

\section{Discussion}

Much attention has been paid to psychological distress among patients with breast cancer (Srivastava et al., 2016) Mostly related to fear of recurrence, depression and anxiety are considered as the most prevalent psychological disorders in breast cancer patients (Schmid-Büchi et al., 2008) and can cause 
mental disturbance in cancer patients (Karakas \& Okanli, 2014). The results of this study indicate that there is a substantial relationship between anxiety, depression, and quality of life in breast cancer patients, which is in line with several studies. Previous research has indicated the effect of anxiety and depression on quality of life (Buzgova, Jarosova, \& Hajnova, 2015; Skarstein et al., 2000; Schleife et al., 2014; Ell et al., 2005; Alacacioglu et al., 2010; Bektas \& Demir, 2016; Zenger et al., 2010; Frick, Tyroller, \& Panzer, 2007; Tsunoda et al., 2005; So et al., 2010; Hutter et al., 2013; Karakoyun-Celik et al., 2010). In addition, anxiety may also cause delay or interference with the seeking of medical care (Spencer, Carver, \& Price, 1998). Along with immunosuppressive effects, long-term anxiety compromises the patient and might impair cognitive functioning level, especially when important health decisions must be made (Van Oers \& Schlebusch, 2013). The subjective feeling about treatment ineffectiveness may trigger an anxious reaction concerning the disease progress or life expectancy (Wong \& Bramwell, 1992). Massie and Holland (Massie \& Holland, 1987) described four anxiety-inducing situations, namely, while waiting to receive their diagnosis, prior to major diagnostic tests, before an operation, and while waiting for test results. Upon the diagnosis of breast cancer, anxiety can lead to inability to concentrate, diminished sleep, appetite loss, irritability, and intrusive thoughts about the future.

Moreover, the results of the present study showed that patients with breast cancer experience high levels of depression, accompanied with low quality of life. To justify this, depression causes increased suicide risk (Misono et al., 2008) and reduced survival expectation (Satin et al., 2009). Buzgova (2015) also found that physical, emotional, and social functioning are negatively affected by anxiety and depression. Research has also shown that depression has adverse effects on interpersonal relationships, job performance, stress, and perceptions of health and physical symptoms (Ng et al., 2016).

This study showed that there was no difference between different age groups in terms of anxiety and depression. Tavoli et al (2007) found that age has no effect on depression. Contrary to the findings of the present study, several studies have reported that middle-aged and elderly patients experience higher anxiety and depression (Nikbakhsh et al., 2014; Ozkan, Ogce, \& Koca, 2007).

Hopelessness and despair have been widely reported to possibly increase anxiety and depression (Kavradım \& Ozer, 2014). Moreover, psychological symptoms may reduce the efficiency of chemotherapy for breast cancer patients (Su et al., 2005). Although there is dearth of research on the mechanism through which psychological distress negatively influences the efficacy of the treatment, the role of psychological distress in causing stress, which can, in turn, change hormonal and neuronal secretions and thus the biological activity of breast cancer cells, has been documented (Drell IV et al., 2003). Therefore, the early diagnosis as well as effective management of psychological symptoms can enhance the effectiveness of cancer treatment (Wardle et al., 2015). Overall, the aforementioned points imply that cancer patients' physical and psychosocial distress can influence their quality of life.

As Pandey et al (2006) maintains, there are four forms of anxiety: situational anxiety, disease-related anxiety, treatment-related anxiety, and exacerbation of pre-treatment anxiety disorder. Untreated anxiety and depression can produce negative effects on patients' control of symptoms, ability to make treatment decisions, compliance with treatment, social interaction, and quality of life (Tel, Tel, \& Doğan, 2011). Hence, diagnosis and treatment of anxiety and depression can considerably improve patients' physical and emotional functioning (Buzgova et al., 2015), substantially enhancing their 
quality of life. To sum up, psychological wellbeing is an important aspect of quality of life for patients with severe diseases like breast cancer. Early diagnosis and treatment of psychological symptoms, such as anxiety and depression, and other psychiatric disorders will increase patients' adjustment to breast cancer and its treatment and, in turn, their quality of life. Therefore, initial assessment as well as subsequent treatment of depression and anxiety could be used to promote psychological health and quality of life among women with breast cancer.

\section{Corresponding Author}

Majid Sadoughi, Assistant Professor of Psychology, University of Kashan, Kashan, Iran, Sadoughi@Kashanu.ac.ir

\section{References}

Alacacioglu, A., Binicier, O., Gungor, O., Oztop, I., Dirioz, M., \& Yilmaz, U. (2010). Quality of life, anxiety, and depression in Turkish colorectal cancer patients. Supportive care in cancer, 18(4), 417-421.

Bektas, D. K., \& Demir, S. (2016). Anxiety, Depression Levels and Quality of Life in Patients with Gastrointestinal Cancer in Turkey. Asian Pacific Journal of Cancer Prevention, 17(2), 723-731.

Bredal, I. S., Sandvik, L., Karesen, R., \& Ekeberg, O. (2011). Prognostic value of health-related qualityof-life parameters in early-stage breast cancer: an 8-year follow-up study. Psycho-Oncology, 20(10), 1102-1107.

Brown, D. J., McMillan, D. C., \& Milroy, R. (2005). The correlation between fatigue, physical function, the systemic inflammatory response, and psychological distress in patients with advanced lung cancer. Cancer, 103(2), 377-382.

Buzgova, R., Jarosova, D., \& Hajnova, E. (2015). Assessing anxiety and depression with respect to the quality of life in cancer inpatients receiving palliative care. European Journal of Oncology Nursing, 19(6), 667-672.

Dedeli, O., Fadiloglu, C., \& Uslu, R. (2008). A survey of functional living and social support in patients with cancer. J Turk Oncol, 23, 132-139.

Demir, M. (2015). Effects of Laughter Therapy on Anxiety, Stress, Depression and Quality of Life in Cancer Patients. Journal of Cancer Science \& Therapy, 2015.

Drell IV, T., Joseph, J., Lang, K., Niggemann, B., Zaenker, K., \& Entschladen, F. (2003). Effects of neurotransmitters on the chemokinesis and chemotaxis of MDA-MB-468 human breast carcinoma cells. Breast cancer research and treatment, 80(1), 63-70.

Ell, K., Sanchez, K., Vourlekis, B., Lee, P.-J., Dwight-Johnson, M., Lagomasino, I., . . Russell, C. (2005). Depression, correlates of depression, and receipt of depression care among low-income women with breast or gynecologic cancer. Journal of Clinical Oncology, 23(13), 3052-3060.

Ferrell, B. R., Grant, M., Funk, B., Otis-Green, S., \& Garcia, N. (1997). Quality of life in breast cancer: Part I: Physical and social well-being. Cancer Nursing, 20(6), 398-408.

Frick, E., Tyroller, M., \& Panzer, M. (2007). Anxiety, depression and quality of life of cancer patients undergoing radiation therapy: a cross-sectional study in a community hospital outpatient centre. European journal of cancer care, 16(2), 130-136.

Hussein, I. (2011). The relationship between perfectionism and loneliness, and quality of life of medical students in Guilan province. M.S. Thesis, Islamic Azad University of Tonokabon. 
Hutter, N., Vogel, B., Alexander, T., Baumeister, H., Helmes, A., \& Bengel, J. (2013). Are depression and anxiety determinants or indicators of quality of life in breast cancer patients? Psychology, health \& medicine, 18(4), 412-419.

Karakas, S. A., \& Okanli, A. (2014). The relationship between meaning of illness, anxiety depression, and quality of life for cancer patients. Collegium antropologicum, 38(3), 939-944.

Karakoyun-Celik, O., Gorken, I., Sahin, S., Orcin, E., Alanyali, H., \& Kinay, M. (2010). Depression and anxiety levels in woman under follow-up for breast cancer: relationship to coping with cancer and quality of life. Medical Oncology, 27(1), 108-113.

Kavradım, S. T., \& Ozer, Z. C. (2014). Hope in patients with cancer. Psikiyatride Guncel YaklasimlarCurrent Approaches in Psychiatry, 6(2), 154-164.

Kutlu, R., Civi, S., Borüban, M., \& Demir, A. (2011). Depression and the factors affecting the quality of life in cancer patients. SelCuk Üniv Tıp Derg, 27(3), 149-153.

Li, Y., \& Yuan, C. (2011). Levels of fatigue in Chinese women with breast cancer and its correlates: A cross-sectional questionnaire survey. Journal of the American Academy of Nurse Practitioners, 23(3), 153-160.

Massie, M. J., \& Holland, J. C. (1987). The cancer patient with pain: psychiatric complications and their management. The Medical clinics of North America, 71(2), 243.

Misono, S., Weiss, N. S., Fann, J. R., Redman, M., \& Yueh, B. (2008). Incidence of suicide in persons with cancer. Journal of Clinical Oncology, 26(29), 4731-4738.

Ng, C., Mohamed, S., See, M., Harun, F., Sulaiman, A., Zainal, N., \& Taib, N. (2016). Anxiety, depression, perceived social support and quality of life in Malaysian breast cancer patients: A 1-year prospective study. European Psychiatry, 33, S419.

Nikbakhsh, N., Moudi, S., Abbasian, S., \& Khafri, S. (2014). Prevalence of depression and anxiety among cancer patients. Caspian J Intern Med, 5(3), 167-170.

O'Neil, A., Stevenson, C. E., Williams, E. D., Mortimer, D., Oldenburg, B., \& Sanderson, K. (2013). The health-related quality of life burden of co-morbid cardiovascular disease and major depressive disorder in Australia: findings from a population-based, cross-sectional study. Quality of life research, 22(1), 37-44.

Ozkan, S., Ogce, F., \& Koca, A. (2007). Determination of the presence of depression, anxiety and disability of breast and gastro intestinal system cancer patients. J Ege University School of Nursing, 23, 69-80.

Pandey, M., Sarita, G. P., Devi, N., Thomas, B. C., Hussain, B. M., \& Krishnan, R. (2006). Distress, anxiety, and depression in cancer patients undergoing chemotherapy. World Journal of Surgical Oncology, 4(1), 1.

Petrie, W., Logan, J., \& DeGrasse, C. (2001). Research review of the supportive care needs of spouses of women with breast cancer. Paper presented at the Oncology nursing forum.

Rajandram, R. K., Ho, S. M., Samman, N., Chan, N., McGrath, C., \& Zwahlen, R. A. (2011). Interaction of hope and optimism with anxiety and depression in a specific group of cancer survivors: a preliminary study. BMC research notes, 4(1), 519.

Safaee, A., \& Dehkordi, M. B. (2007). Validation study of a quality of life (QOL) questionnaire for use in Iran. Asian Pac J Cancer Prev, 8(4), 543-546.

Satin, J. R., Linden, W., \& Phillips, M. J. (2009). Depression as a predictor of disease progression and mortality in cancer patients. Cancer, 115(22), 5349-5361. 
Schleife, H., Sachtleben, C., Barboza, C. F., Singer, S., \& Hinz, A. (2014). Anxiety, depression, and quality of life in German ambulatory breast cancer patients. Breast Cancer, 21(2), 208-213.

Schmid-Büchi, S., Halfens, R. J., Dassen, T., \& Van Den Borne, B. (2008). A review of psychosocial needs of breast-cancer patients and their relatives. Journal of clinical nursing, 17(21), 28952909.

Shim, E.-J., Mehnert, A., Koyama, A., Cho, S.-J., Inui, H., Paik, N.-S., \& Koch, U. (2006). Health-related quality of life in breast cancer: A cross-cultural survey of German, Japanese, and South Korean patients. Breast cancer research and treatment, 99(3), 341-350.

Singer, S., Das-Munshi, J., \& Brähler, E. (2009). Prevalence of mental health conditions in cancer patients in acute care-a meta-analysis. Annals of Oncology, mdp515.

Skarstein, J., Aass, N., Fosså, S. D., Skovlund, E., \& Dahl, A. A. (2000). Anxiety and depression in cancer patients: relation between the Hospital Anxiety and Depression Scale and the European Organization for Research and Treatment of Cancer Core Quality of Life Questionnaire. Journal of psychosomatic research, 49(1), 27-34.

So, W. K., Marsh, G., Ling, W., Leung, F., Lo, J. C., Yeung, M., \& Li, G. K. (2010). Anxiety, depression and quality of life among Chinese breast cancer patients during adjuvant therapy. European Journal of Oncology Nursing, 14(1), 17-22.

Spencer, S., Carver, C. S., \& Price, A. (1998). Psychological and social factors in adaptation. Psychooncology, 2, 211-222.

Srivastava, V., Ansari, M. A., Kumar, A., Shah, A. G., Meena, R. K., Sevach, P., \& Singh, O. P. (2016). Study of Anxiety and Depression among Breast Cancer Patients from North India. Clinical Psychiatry.

Su, F., Ouyang, N., Zhu, P., Ouyang, N., Jia, W., Gong, C., . . Song, E. (2005). Psychological stress induces chemoresistance in breast cancer by upregulating mdr1. Biochemical and biophysical research communications, 329(3), 888-897.

Tavoli, A., Mohagheghi, M. A., Montazeri, A., Roshan, R., Tavoli, Z., \& Omidvari, S. (2007). Anxiety and depression in patients with gastrointestinal cancer: does knowledge of cancer diagnosis matter? BMC gastroenterology, 7(1), 1.

Tel, H., Tel, H., \& Doğan, S. (2011). Fatigue, anxiety and depression in cancer patients. Neurology, psychiatry and brain research, 17(2), 42-45.

Tokgoz, G. (2008). Prevalence of major depression in patients with cancer and related factors.

Tsunoda, A., Nakao, K., Hiratsuka, K., Yasuda, N., Shibusawa, M., \& Kusano, M. (2005). Anxiety, depression and quality of life in colorectal cancer patients. International Journal of Clinical Oncology, 10(6), 411-417.

Van Oers, H. M., \& Schlebusch, L. (2013). Anxiety and the patient with breast cancer: a review of current research and practice. South African Family Practice, 55(6), 525-529.

Wardle, J., Robb, K., Vernon, S., \& Waller, J. (2015). Screening for prevention and early diagnosis of cancer. American Psychologist, 70(2), 119.

Wong, C. A., \& Bramwell, L. (1992). Uncertainty and anxiety after mastectomy for breast cancer. Cancer Nursing, 15(5), 363-371.

Zenger, M., Brix, C., Borowski, J., Stolzenburg, J. U., \& Hinz, A. (2010). The impact of optimism on anxiety, depression and quality of life in urogenital cancer patients. Psycho-Oncology, 19(8), 879-886. 